\title{
10-year Analysis of Assisted Reproductive Technique Outcomes at a University Hospital
}

\author{
(D) Gökhan Artar¹, (D) Berna Aslan Çetin², (D) Tamer Erel³
}

${ }_{1}^{1}$ Bağcılar Training and Research Hospital, Clinic of Gynecology and Obstetrics, Istanbul, Turkey ${ }^{2}$ Kanuni Sultan Süleyman Training and Research Hospital, Clinic of Gynecology and Obstetrics, istanbul, Turkey 3istanbul University-Cerrahpaşa, Cerrahpaşa Faculty of Medicine, Department of Gynecology and Obstetrics, Istanbul, Turkey

\section{Abstract}

Objective: Our aim is to investigate the 10-year results of assisted reproductive technique (ART) cycles in our in vitro fertilization (IVF) clinic and to evaluate the effects of treatment protocols on ART outcomes.

Methods: Medical records of 2.795 IVF cycles of 1.964 infertile couples who were admitted to our IVF unit between 1998 and 2007 were evaluated retrospectively. A short or long protocol was performed with a gonadotropin-releasing hormone (GnRH)-analog and a GnRHantagonist. Factors that may affect ART success or failure were evaluated and interpreted.

Results: The pregnancy rates per IVF cycle and per transfer were $21.07 \%$ and $24.4 \%$, respectively. The highest pregnancy rate was attained when the cause of infertility was unexplained $(p<0.001)$. Treatment with the long protocol resulted in a higher pregnancy rate than treatment with either the short or the long the antagonist protocol $(p<0.001)$. The pregnancy rate was higher when the third-day step-down protocol was applied, compared with any of the fifth-day step-down, continuous-dose, and step-up protocols. The number of cycles, duration of infertility, age, follicle stimulating hormone level on the $3^{\text {rd }}$ day of menstruation, E2 level measured on the day of human chorionic gonadotropin, total gonadotropin dose, total number of oocytes collected, and number of total embryos transferred affected the success rate of ART per cycle.

Conclusion: Unexplained infertility, use of the long protocol, application of the third-day step-down protocol, and application of intracytoplasmic sperm injection and luteal support are associated with higher pregnancy rates. The number of oocytes collected, number of embryos transferred, and the quality of the transferred embryos are important factors affecting pregnancy rates.

Keywords: Assisted reproductive technology, pregnancy, infertility

\section{INTRODUCTION}

Infertility is defined as failure to achieve a clinical pregnancy after 12 months or more of regular unprotected sexual intercourse. Infertility affects $10 \%-15 \%$ of couples in the reproductive age group (1). According to the findings of the Infertility Diagnosis and Treatment Group of the World Health Organization, the cause of infertility was attributed to the female in $37 \%$ of cases, the male in $8 \%$, and the couple in $35 \%$, while in $5 \%$ of cases, a cause was not found (unexplained infertility). Over the course of the study, $15 \%$ of the couples conceived (2). Female infertility may be caused by tuboperitoneal factors (25\%-30\%), ovulatory dysfunction (15\%-20\%), or cervical and uterine factors (5\%-10\%) (2).

A variety of treatment modalities are offered to infertile couples. In vitro fertilization (IVF) and embryo transfer (ET) is one such technique. It is generally applied after other treatment methods, but in some cases, it may be the first option. In 1978, Steptoe and Edwards obtained a single preovulatory human oocyte by a natural cycle, conducted IVF and transferred the resulting embryo to the uterus in the blastocyst stage, resulting in a term delivery 
(3). Over the years, significant improvements have been made to the techniques of ovulatory stimulation, oocyte collection, oocyte and embryo culture, embryos cryopreservation, and ET (4). IVF is a controlled ovarian stimulation performed by external gonadotropin administration, oocyte collection under transvaginal ultrasonography (USG), fertilization in the laboratory, and transcervical transfer of embryos to the uterus.

The aim of this study was to investigate the results of assisted reproductive technique (ART) cycles in our IVF unit and to investigate the factors confounding ART outcomes.

\section{METHODS}

In this study, 2.795 ART cycles performed in 1964 infertile couples were evaluated retrospectively in a 10-year period between January 1998 and December 2007. Indications for initiation of treatment of patients were classified as tubal factors, male factors, unexplained infertility, and ovarian failure. The study was conducted according to the Helsinki Declaration.

Patient histories were taken. Gynecological examinations were performed. Following gynecological examination, transvaginal USG was performed. Sperm analysis was performed prior to ART. In order to determine the ovarian reserve, venous blood was sampled on the third day of menstruation (early follicular phase); follicle stimulating hormone (FSH), luteinizing hormone (LH), and estradiol levels were measured using enzyme immunoassay kits. Hysterosalphingography was routinely performed prior to treatment.

A short or long protocol was performed with a gonadotropinreleasing hormone (GnRH)-analog and a GnRH-antagonist.

1. Long protocol: Administration of a $\mathrm{GnRH}$-analog was started on the $21^{\text {st }}$ day of the menstrual cycle, and gonadotropin was added on the second to third day of the next cycle and continued until the day of human chorionic gonadotropin (HCG) administration.

2. Short protocol: Administration of a GnRH-analog was started on the first day of the menstrual cycle, and gonadotropin was added on the second to third day of the cycle and was continued until the day of HCG administration.

On the third day of ovulation induction, age and body mass index was taken into consideration, and 225-300 IU gonadotropin was started. Follicular development was followed by daily E2 evaluations and by transvaginal USG. It was decided that the dose of E2 in the late follicular phase should be increased by $50 \%$ compared with the previous day, and follicles increased by $1-3 \mathrm{~mm} /$ day. When at least 2 follicles passed 16 millimeters, and the E2 per follicle exceeded $150 \mathrm{pg} / \mathrm{dL}$, for the LH peak 5,000 or 10,000 IU HCG was administered. Follicle aspiration was performed 36 hours after HCG administration. The follicles were collected with the help of transvaginal USG. Each follicle of 11 millimeters and above was aspirated.

Follicle aspiration was performed with transvaginal ultrasound. The vaginal mucosa was cleaned with warm saline prior to the procedure. Follicular aspiration was performed under intravenous analgesia. Follicle aspiration was performed by entering the vaginal side walls and fornices with a single-lumen aspiration needle, which could be attached to the vaginal ultrasound by an adapter. After this examination, the sperm were made ready for insemination or intracytoplasmic sperm injection (ICSI) by swim-up or rotating according to their density.

As luteal-phase support, oral, vaginal, or muscular progesterone supplementation or muscular HCG was administered up to 12 weeks of gestation.

Pregnancy was determined by serum $\beta$-HCG measurements at 12 days after ET. In patients with $\beta$-HCG levels above $10 \mathrm{mIU} / \mathrm{mL}$, measurements were monitored at 7-14-day intervals. Clinical pregnancy was defined as the presence of at least one gestational sac with fetal cardiac activity, detected by transvaginal USG.

Ethics Committee of İstanbul University-Cerrahpaşa, Cerrahpaşa Faculty of Medicine, (number: 4467, date: 05.02.2008).

\section{Statistical Analysis}

SPSS Statistics, Version 17 (SPSS Inc.; Chicago, IL, USA) was used for statistical analysis. In the biostatistical analysis of the study, variables were defined by the mean, standard deviation, frequency, and percentages, and the chi-square and Fisher exact tests were used to compare frequencies and percentages. The Mann-Whitney $\mathrm{U}$ test was used for non-parametric variables. In order to compare the mean of the variables with the normal distribution, a t-test was used in the two groups. Multivariate stepwise logistic regression analysis was used for regression analysis. $\mathrm{P}<0.05$ was considered as statistically significant.

\section{RESULTS}

A total of 1964 cases were evaluated. The total number of cycles was 2,795. A total of 2,405 ETs were performed. The total number of pregnancies was 589 . The pregnancy rate per cycle was $21.07 \%$. The rate of pregnancy per ET was $24.4 \%$.

Cases of patients admitted to our inpatient clinic due to infertility were examined according to their etiological factors: 1,982 (70.9\%) had a male factor, 487 (17.4\%) had a tuboperitoneal factor, 282 (10.1\%) had unexplained infertility, and 44 (1\%) had 
ovarian failure. In these groups, the rates of pregnancy per cycle were $22.5 \%$ in the male factor group ( $41.9 \%$ in ET), $18.6 \%$ in the tuboperitoneal factor group (21.5\% in ET), $31.5 \%$ in the unexplained infertility group (35\% in ET), and 10.7\% (13.6\% pregnancy rate per ET) in the ovarian failure group. In the group with unexplained infertility, the pregnancy rate per cycle was significantly higher than that in the other groups $(p<0.001)$.

In 2.795 cycles, the GnRH-analog long protocol was used in 1.713 cycles, the GnRH-analog short protocol in 954 cycles and the GnRH-antagonist protocol in 128 cycles. The pregnancy rates per cycle in these groups were $24.3 \%, 16.0 \%$, and $14.8 \%$, respectively. In the $\mathrm{GnRH}$-analog long protocol group, the pregnancy rate was found to be significantly higher than that in the other groups $(p<0.001)$.

In 1.105 cycles, a step-down gonadotropin protocol was applied with dose reduction on the third day. A total of 281 (25.4\%) pregnancies were obtained in this group. In 152 cycles, a stepwise decreasing gonadotropin protocol was applied, and dose reduction was applied on the fifth day. A total of 29 (19.1\%) pregnancies were obtained in this group. In 1,390 cycles, a fixed-dose gonadotropin protocol was applied, and 258 (18.6\%) pregnancies were obtained in this group. The step-up gonadotropin protocol was applied in 148 cycles. A total of 21 (14.2\%) pregnancies were obtained in this group. The pregnancy rates per cycle in the third-day decreasing group were found to be significantly higher than those in the other group treatment protocols $(p<0.001)$.

Out of 2.795 cycles, 1.051 (37.7\%) cycles were treated with human menopausal gonadotropin (HMG), 1.566 (56\%) with pure FSH, 113 (4\%) with urinary FSH, and 65 (2.3\%) with different drugs. The pregnancy rates per cycle in these groups were $21 \%$, $21 \%, 23.8 \%$, and $18.4 \%$, respectively. There were no statistically significant differences in pregnancy rates according to these ratios $(p>0.05)$.

A GnRH-analog was used in 2,656 (95.4\%) cycles and GnRHantagonists in $129(4.6 \%)$ cycles. The pregnancy rate per cycle was $21.4 \%$ and $14.7 \%$, respectively. Pregnancy rates among the $\mathrm{GnRH}$-analog and GnRH-antagonist groups were significantly higher in the Leuprolid asetat group $(p=0.002)$. In addition, when only GnRH-analog agents were compared, pregnancy rates were significantly higher in the Leuprolid asetat group $(p=0.002)$.

Oral progesterone, intramuscular (IM) progesterone, HCG, and vaginal progesterone were used as luteal-phase support. Pregnancy rates per cycle were $24.1 \%$ in the group using oral progesterone, $26.7 \%$ in the IM progesterone group, $24.9 \%$ in the vaginal progesterone group, $24.2 \%$ in the HCG group, and $24.1 \%$ in the HCG and progesterone group. There were no statistically significant differences between the groups $(p>0.05)$.

No difference was found in LH, PRL, E2, and thyroid stimulating hormone levels between the clinically positive and negative patients. Infertility duration, age, and the FSH level on the third day of menstruation were higher in the group that did not achieve clinical pregnancy (Table 1).

The total number of ART cycles, serum E2 level on the day of HCG administration, total gonadotropin dose, total number of oocytes collected, number of oocytes used for ICSI, number of oocytes used for IVF, total number of oocytes fertilized for ICSI, total number of oocytes fertilized for IVF, number of total embryos transferred, number of grade 1 embryos transferred, number of grade 2 embryos transferred, number of metaphase 2 oocytes, and number of prophase 1 oocytes (germinal vesicle) were significantly higher in the group that achieved clinical pregnancy (Table 2).

In logistic regression analysis, the number of transferred embryos $[p=0.06$, odds ratio (OR): 1.38$]$ was found to be poorly correlated with pregnancy success, although not statistically significant; the relation between the use of the ICSI method ( $p=0.03$, OR: 1.13) and pregnancy success was found to be the most statistically significant, among all the variables tested (Table 3).

\section{DISCUSSION}

The rate of pregnancy per ART cycle in our clinic was $21.1 \%$. The rate of pregnancy per ET was $24.4 \%$. These rates are close to those reported by the European Society of Human Reproduction and

\begin{tabular}{|l|l|l|l|}
\hline \multicolumn{4}{|l|}{ Table 1. Demographic and clinical features of the patients } \\
\hline & $\begin{array}{l}\text { Clinical } \\
\text { pregnancy } \\
\text { negative } \\
\text { (n=1.375) }\end{array}$ & $\begin{array}{l}\text { Clinical } \\
\text { pregnancy } \\
\text { positive } \\
\text { (n=589) }\end{array}$ & p value \\
\hline Age & $33.43 \pm 4.82$ & $31.84 \pm 3.98$ & $<\mathbf{0 . 0 0 1}$ \\
\hline $\begin{array}{l}\text { Infertility duration } \\
\text { (years) }\end{array}$ & $8.91 \pm 3.23$ & $7.80 \pm 2.84$ & $<\mathbf{0 . 0 0 1}$ \\
\hline BMI $\left(\mathrm{kg} / \mathrm{m}^{2}\right)$ & $25.70 \pm 4.87$ & $24.17 \pm 4.66$ & $<\mathbf{0 . 0 0 1}$ \\
\hline FSH $(\mathrm{mIU} / \mathrm{mL})$ & $7.98 \pm 3.43$ & $6.75 \pm 3.23$ & $<\mathbf{0 . 0 0 1}$ \\
\hline LH $(\mathrm{mIU} / \mathrm{mL})$ & $5.57 \pm 2.66$ & $5.62 \pm 2.76$ & 0.794 \\
\hline Estradiol $(\mathrm{pg} / \mathrm{mL})$ & $54.87 \pm 12.54$ & $49.66 \pm 12.98$ & 0.227 \\
\hline Prolactin $(\mathrm{ng} / \mathrm{mL})$ & $20.96 \pm 7.44$ & $20.94 \pm 6.98$ & 0.994 \\
\hline TSH ( $\mu$ IU/mL) & $2.14 \pm 1.12$ & $2.13 \pm 1.32$ & 0.930 \\
\hline Total number of cycles & $1(1-2)$ & $1(1-2)$ & $\mathbf{0 . 0 2 8}$ \\
\hline $\begin{array}{l}\text { BMI: Body mass index, FSH: Follicle stimulating hormone, LH: Luteinizing hormone, } \\
\text { TSH: Thyroid stimulating hormone }\end{array}$ & & \\
\hline
\end{tabular}


Embryology (ESHRE) for ET in 2005 (28.8\%) (5). The society for ART (SART) reported in 2001 that the pregnancy rate per ET was 40\% (6). The success rate of our clinic is consistent with the pregnancy rate reported by ESHRE, but lower than that reported by the SART.

\begin{tabular}{|c|c|c|c|}
\hline & $\begin{array}{l}\text { Clinical } \\
\text { pregnancy } \\
\text { negative } \\
(n=2.206)\end{array}$ & $\begin{array}{l}\text { Clinical } \\
\text { pregnancy } \\
\text { positive } \\
(n=589)\end{array}$ & $p$ value \\
\hline $\begin{array}{l}\text { Induction duration } \\
\text { (days) }\end{array}$ & $8.64 \pm 2.32$ & $8.76 \pm 1.54$ & 0.154 \\
\hline $\begin{array}{l}\text { LH level at HCG day } \\
(\mathrm{mIU} / \mathrm{mL})\end{array}$ & $3.46 \pm 1.55$ & $3.84 \pm 1.67$ & 0.550 \\
\hline $\begin{array}{l}\text { Estradiol level at } \\
\text { HCG day }(\mathrm{pg} / \mathrm{mL})\end{array}$ & $1853.37 \pm 846.44$ & $2230.20 \pm 987.22$ & $<0.001$ \\
\hline $\begin{array}{l}\text { Progesterone level } \\
\text { at HCG day }(\mathrm{ng} / \mathrm{mL})\end{array}$ & $1.22 \pm 0.66$ & $0.94 \pm 0.55$ & 0.563 \\
\hline $\begin{array}{l}\text { Endometrial } \\
\text { thickness at HCG } \\
\text { day }(\mathrm{mm})\end{array}$ & $10.42 \pm 2.67$ & $10.52 \pm 2.33$ & 0.794 \\
\hline $\begin{array}{l}\text { Total number of } \\
\text { oocytes }\end{array}$ & $8(5-11)$ & $11(7-15)$ & $<0.001$ \\
\hline $\begin{array}{l}\text { Number of fertilized } \\
\text { oocytes }\end{array}$ & $3(4-6)$ & $5(3-7)$ & $<0.001$ \\
\hline $\begin{array}{l}\text { Number of } \\
\text { transferred } \\
\text { blastocytes }\end{array}$ & $0(0-1)$ & $0(0-1)$ & 0.811 \\
\hline $\begin{array}{l}\text { Number of } \\
\text { metaphase } 1 \\
\text { oocytes }\end{array}$ & $0(0-1)$ & $0(0-1)$ & 0.862 \\
\hline $\begin{array}{l}\text { Number of } \\
\text { metaphase } 2 \\
\text { oocytes }\end{array}$ & $2(1-3)$ & $2(1-4)$ & $<0.001$ \\
\hline $\begin{array}{l}\text { Number of } \\
\text { prophase } 1 \\
\text { (germinal vesicle) } \\
\text { oocytes }\end{array}$ & $0(0-1)$ & $0(0-1)$ & 0.065 \\
\hline $\begin{array}{l}\text { Total number of } \\
\text { transferred embryos }\end{array}$ & $2(1-4)$ & $4(2-6)$ & $<0.001$ \\
\hline $\begin{array}{l}\text { Number of } \\
\text { transferred grade } 1 \\
\text { embryos }\end{array}$ & $1(0-2)$ & $2(1-3)$ & $<0.001$ \\
\hline $\begin{array}{l}\text { Number of } \\
\text { transferred grade } 2 \\
\text { embryos }\end{array}$ & $1(0-2)$ & $2(1-3)$ & $<0.001$ \\
\hline $\begin{array}{l}\text { Number of } \\
\text { transferred grade } 3 \\
\text { embryos }\end{array}$ & $0(0-1)$ & $0(0-1)$ & 0.294 \\
\hline $\begin{array}{l}\text { Number of } \\
\text { transferred grade } 4 \\
\text { embryos }\end{array}$ & $0(0-1)$ & $0(0-1)$ & 0.332 \\
\hline $\begin{array}{l}\text { Number of } \\
\text { postmature oocyte }\end{array}$ & $3(1-5)$ & $5(3-8)$ & $<0.001$ \\
\hline
\end{tabular}

A variety of reasons may account for this difference. These include differences in ovulation induction protocols, variability between patient groups, and different ET techniques of physicians working in our IVF unit. Pregnancy rates per cycle are different between patient groups and between different treatment protocols. Male factor infertility was the major etiological reason for patient admission to our IVF unit. This was followed by tuboperitoneal factors and unexplained infertility. When the pregnancy rates per cycle according to etiological factors were evaluated, we found that the highest success rate was with unexplained infertility [31.5\% (pregnancy rate per ET 35\%)] group. This was followed by male factor [22.5\% (pregnancy rate $41 \%$ )] and tuboperitoneal factor [18.6\% (21.5\% per ET)]. Qublan et al. (7) reported 891 ART cycles with the following etiologies: Male factor (17.8\%), endometriosis (17.6\%), tubal factor (31.6\%), and unexplained infertility (41.1\%). They found that patients with unexplained infertility had higher pregnancy rates.

There are many reports suggesting that there is no difference in randomized studies comparing ART protocols. Similar

\begin{tabular}{|l|l|l|}
\hline \multicolumn{3}{|l|}{ Table 3. Multivariate stepwise logistic regression analysis } \\
\hline & OR & $\mathbf{p}$ \\
\hline Number of transferred embryos & $1.38(0.98-1.94)$ & 0.062 \\
\hline ICSI method & $1.13(1.01-1.26)$ & $\mathbf{0 . 0 3 1}$ \\
\hline Number of fertilized oocytes & $2.26(1.04-4.87)$ & $\mathbf{0 . 0 4 5}$ \\
\hline Age & $1.34(0.98-1.85)$ & 0.061 \\
\hline Infertility duration & $0.94(0.79-1.12)$ & 0.559 \\
\hline Induction duration & $2.10(0.96-4.56)$ & 0.067 \\
\hline LH level at HCG day & $0.79(0.58-1.08)$ & 0.143 \\
\hline Estradiol level at HCG day & $1.02(0.74-1.40)$ & 0.904 \\
\hline Endometrial thickness at HCG day & $1.35(0.67-2.72)$ & 0.392 \\
\hline Number of transferred blastocytes & $0.39(0.02-2.20)$ & 0.287 \\
\hline Number of metaphase 1 oocytes & $0.97(0.93-1.01)$ & 0.255 \\
\hline Number of metaphase 2 oocytes & $0.77(0.44-1.34)$ & 0.398 \\
\hline $\begin{array}{l}\text { Number of prophase 1 (germinal } \\
\text { vesicle) oocytes }\end{array}$ & $0.80(0.28-2.30)$ & 0.686 \\
\hline Total number of transferred embryos & $1.43(0.92-2.23)$ & 0.105 \\
\hline $\begin{array}{l}\text { Number of transferred grade 1 } \\
\text { embryos }\end{array}$ & $1.31(0.90-1.90)$ & 0.147 \\
\hline $\begin{array}{l}\text { Number of transferred grade 2 } \\
\text { embryos }\end{array}$ & $1.33(0.94-1.89)$ & 0.109 \\
\hline $\begin{array}{l}\text { Number of transferred grade 3 } \\
\text { embryos }\end{array}$ & $0.76(0.33-1.75)$ & 0.534 \\
\hline $\begin{array}{l}\text { Number of transferred grade 4 } \\
\text { embryos }\end{array}$ & $0.26(0.04-1.62)$ & 0.152 \\
\hline Number of postmature oocyte & $0.80(0.35-1.83)$ & 0.605 \\
\hline $\begin{array}{l}\text { ICSI: Intracytoplasmic sperm injection, LH: Luteinizing hormone, HCG: Human } \\
\text { chorionic gonadotropin, OR: Odds ratio }\end{array}$ & \\
\hline
\end{tabular}


pregnancy rates have been found in clinical studies comparing standard long $\mathrm{GnRH}$-analog protocols with $\mathrm{GnRH}$-antagonist protocols $(8,9)$. In a clinical study comparing the GnRHantagonist protocol with the standard long GnRH-analog protocol, Firouzabadi et al. (10) did not find a clinically significant difference between these two groups. Al-Inany and Aboulghar (11) compared GnRH-analog long protocol cycles with GnRH-antagonist cycles and found that the GnRH-antagonist group had significantly lower pregnancy rates than the GnRHanalog group (10). However, studies have also found the GnRHantagonist group to be more successful $(11,12)$. In a metaanalysis comparing the GnRH-analog long agonist protocol with the short GnRH-analog protocol, higher pregnancy rates were obtained with the GnRH-analog long protocol (13). We used the long GnRH-analog protocol, the short GnRH-analog protocol, and the $\mathrm{GnRH}$-antagonist protocols, and the long GnRH-analog protocol was more successful. We have used the short GnRH-analog and GnRH-antagonist protocols frequently in patients with poor responses. Therefore, lower success rates may have been achieved.

A meta-analysis comparing urinary FSH with purified FSH in the literature showed similar pregnancy rates (14). In a study comparing urinary FSH with purified FSH, no significant difference was found between the two groups in terms of the clinical pregnancy rate and mean number of collected oocytes (15). However, in the meta-analysis of a large number of different studies, purified FSH was associated with a higher pregnancy success rate than urinary FSH (16). In a study comparing urinary FSH with purified FSH, the clinical pregnancy rate per ET was higher in the purified FSH group (17). In a meta-analysis of five similar studies, urinary FSHs were found to be more successful (18). In a study comparing HMG with purified FSH, the live birth rate with HMG was significantly higher (19). These results show that there is no consensus on the superiority of any drug against another. In our retrospective study, we found that there was no difference in pregnancy rates between pure gonadotropins and urinary gonadotropins.

A wide variety of agents have been proposed in the literature for luteal-phase support after ET. These include progesterone, HCG, and GnRH analogs. In a meta-analysis of 30 randomized studies comparing the use of progesterone and the use of supplemental HCG in the literature, it was found that vaginal use of progesterone was associated with a higher implantation rate than oral use (20). It was determined that IM use of progesterone was associated with higher clinical pregnancy rates, compared with non-use, and no difference was found between oral and vaginal progesterone use. It was observed that HCG administration was associated with higher clinical pregnancy rates, compared with those in the untreated group and the groups treated with oral progesterone, and there was no difference between vaginal and IM use of progesterone (20). The efficacy of HCG compared with progesterone showed similar results, but it has been suggested that HCG increases the ovarian hyperstimulation syndrome risk (21). It has been reported that IM progesterone use results in higher pregnancy success rates than vaginal progesterone use (20). In our study, we found that there were no differences between the various routes of administration of HCG and progesterone after ET.

Increased treatment cycles of ART appear to be associated with poor prognosis and increased maternal age $(22,23)$. In a retrospective study by Martin-Johnston et al. (22) with 2.167 ART cycles, pregnancy rates decreased significantly after the second cycle, and even this decrease was more prominent after 3-5 cycles. They observed that the probability of success decreased with each new treatment cycle. The most significant reduction in pregnancy rates occurred after the third cycle. Therefore, patients who experience three failed cycles should be informed about other treatment options. In a study by Silberstein et al. (23), pregnancy rates and implantation rates decreased in second cycle and reach a plateau in 3-5 cycles. In our study, we found that increasing the number of cycles decreased the ART success and pregnancy rate per cycle.

The gonadotropin dose used is also an important factor affecting the pregnancy rate. We found that increasing the dose of gonadotropin negatively affects pregnancy outcomes. The response to gonadotropin treatment is an indication of the ability of the ovaries to develop follicles directly. In a retrospective study by Martin et al. (24), they found an inverse relationship between the gonadotropin dose and pregnancy rates. This study shows that success in ART cycles depends on the ability of the ovaries to develop an appropriate follicle. The high-dose gonadotropins used are indicative of the inability of the ovaries to develop follicles.

We showed that the number of oocytes collected, number of embryos transferred, and the quality of the transferred embryos are important factors affecting conception. We found that the number of collected oocytes, the number of embryos transferred, and the quality of the transferred embryos increased pregnancy rates. Kably Ambe et al. (25) found in their study that the number of collected oocytes, especially when this number was above 13 , was associated with high pregnancy rates, in support of our findings. 


\section{CONCLUSION}

In summary, the number of ART cycles performed, duration of infertility, maternal age, FSH level on the third day of menstruation, E2 level measured on the day of HCG, total gonadotropin dose, total number of oocytes collected, number of oocytes used for ICSI, number of oocytes used for IVF, total number of oocytes fertilized by ICSI, total number of oocytes fertilized as a result of IVF, number of total embryos transferred, number of grade 1 embryos transferred, number of metaphase 2 oocytes, number of prophase 1 oocytes (germinal vesicles) affect the success of ART per cycle. The limitation of our study is its retrospective design. Future prospective randomized trials with large patient populations evaluating ART success are needed.

\section{Ethics}

Ethics Committee Approval: Ethics Committee of İstanbul University-Cerrahpaşa, Cerrahpașa Faculty of Medicine, (number: 4467, date: 05.02.2008).

Informed Consent: Informed consent is not obtained due to the retrospective nature of this study.

Peer-review: Externally and internally peer-reviewed.

\section{Authorship Contributions}

Concept: G.A., T.E., Design: G.A., Data Collection or Processing: G.A., Analysis or Interpretation: B.A.C.., Literature Search: B.A.C.., Writing: G.A., B.A.Ç.

Conflict of Interest: No conflict of interest was declared by the authors.

Financial Disclosure: The authors declared that this study received no financial support.

\section{REFERENCES}

1. Hanson B, Johnstone E, Dorais J, Silver B, Peterson CM, Hotaling J. Female infertility, infertility-associated diagnoses, and comorbidities: a review. J Assist Reprod Genet 2017;34:167-77.

2. Kwan I, Bhattacharya S, McNeil A, van Rumste MM. Monitoring of stimulated cycles in assisted reproduction (IVF and ICSI). Cochrane Database Syst Rev 2008:CD005289.

3. Simopoulou M, Sfakianoudis K, Maziotis E, Antoniou N, Rapani A, Anifandis G, et al. Are computational applications the "crystal ball" in the IVF laboratory? The evolution from mathematics to artificial intelligence. J Assist Reprod Genet 2018;35:1545-57.

4. Zegers-Hochschild F, Adamson GD, Dyer S, Racowsky C, de Mouzon J, Sokol R, et al. The International Glossary on Infertility and Fertility Care, 2017. Hum Reprod 2017;32:1786-801.

5. Ferraretti AP, Goossens V, de Mouzon J, Bhattacharya S, Castilla JA, Korsak V, et al. Assisted reproductive technology in Europe, 2008: results generated from European registers by ESHRE. Hum Reprod 2012;27:2571-84.

6. Society for Assisted Reproductive Technology; American Society for Reproductive Medicine. Assisted reproductive technology in the United States: 2001 results generated from the American Society for Reproductive Medicine/Society for Assisted Reproductive Technology registry. Fertil Steril 2007;87:1253-66.

7. Qublan HS, Malkawi HY, Tahat YA, Areidah S, Nusair B, Khreisat BM, et al. In-vitro fertilisation treatment: factors affecting its results and outcome. J Obstet Gynaecol 2005;25:689-93.

8. Barmat LI, Chantilis SJ, Hurst BS, Dickey RP. A randomized prospective trial comparing gonadotropin-releasing hormone (GnRH) antagonist/ recombinant follicle-stimulating hormone ( $\mathrm{rFSH}$ ) versus GnRH-agonist/ $\mathrm{rFSH}$ in women pretreated with oral contraceptives before in vitro fertilization. Fertil Steril 2005;83:321-30.

9. Borm G, Mannaerts B. Treatment with the gonadotrophin-releasing hormone antagonist ganirelix in women undergoing ovarian stimulation with recombinant follicle stimulating hormone is effective, safe and convenient: results of a controlled, randomized, multicentre trial. The European Orgalutran Study Group. Hum Reprod 2000;15:1490-8.

10. Firouzabadi RD, Ahmadi S, Oskouian H, Davar R. Comparing GnRH agonist long protocol and $\mathrm{GnRH}$ antagonist protocol in outcome the first cycle of ART. Arch Gynecol Obstet 2010;281:81-5

11. Al-Inany H, Aboulghar M. Gonadotrophin-releasing hormone antagonists for assisted conception. Cochrane Database Syst Rev 2001:CD001750.

12. Cheung LP, Lam PM, Lok IH, Chiu TT, Yeung SY, Tjer CC, et al. GnRH antagonist versus long $\mathrm{GnRH}$ agonist protocol in poor responders undergoing IVF: a randomized controlled trial. Hum Reprod 2005;20:616-21.

13. Daya S. Withdrawn: Gonadotrophin-releasing hormone agonist protocols for pituitary desensitization in in vitro fertilization and gamete intrafallopian transfer cycles. Cochrane Database Syst Rev 2007:CD001299.

14. Filicori M, Cognigni GE, Pocognoli P, Tabarelli C, Ferlini F, Perri T, et al. Comparison of controlled ovarian stimulation with human menopausal gonadotropin or recombinant follicle-stimulating hormone. Fertil Steril 2003;80:390-7.

15. Baker VL, Fujimoto VY, Kettel LM, Adamson GD, Hoehler F, Jones CE, et al. Clinical efficacy of highly purified urinary FSH versus recombinant FSH in volunteers undergoing controlled ovarian stimulation for in vitro fertilization: a randomized, multicenter, investigator-blind trial. Fertil Steril 2009;91:1005-11.

16. Daya S. Methodologic pitfalls in assessing the efficacy of recombinant follicle-stimulating hormone versus human menopausal gonadotropin in assisted reproduction. Fertil Steril 2003;80:1100-4.

17. Franco JG Jr, Baruffi RL, Coelho J, Mauri AL, Petersen CG, Garbellini E. A prospective and randomized study of ovarian stimulation for ICSI with recombinant FSH versus highly purified urinary FSH. Gynecol Endocrinol 2000;14:5-10.

18. van Wely M, Westergaard LG, Bossuyt PM, van der Veen F. Effectiveness of human menopausal gonadotropin versus recombinant folliclestimulating hormone for controlled ovarian hyperstimulation in assisted reproductive cycles: a meta-analysis. Fertil Steril 2003;80:1086-93.

19. Coomarasamy A, Afnan M, Cheema D, van der Veen F, Bossuyt PM, van Wely M. Urinary hMG versus recombinant FSH for controlled ovarian hyperstimulation following an agonist long down-regulation protocol in IVF or ICSI treatment: a systematic review and meta-analysis. Hum Reprod 2008;23:310-5. 
20. Pritts EA, Atwood AK. Luteal phase support in infertility treatment: a meta-analysis of the randomized trials. Hum Reprod 2002;17:2287-99.

21. Yding Andersen C, Vilbour Andersen K. Improving the luteal phase after ovarian stimulation: reviewing new options. Reprod Biomed Online 2014;28:552-9.

22. Martin-Johnston MK, Uhler ML, Grotjan HE, Lifchez AS, Nani JM, Beltsos AN. Lower chance of pregnancy with repeated cycles with in vitro fertilization. J Reprod Med 2009;54:67-72.

23. Silberstein T, Trimarchi JR, Gonzalez L, Keefe DL, Blazar AS. Pregnancy outcome in in vitro fertilization decreases to a plateau with repeated cycles. Fertil Steril 2005;84:1043-5.
24. Martin JR, Mahutte NG, Arici A, Sakkas D. Impact of duration and dose of gonadotrophins on IVF outcomes. Reprod Biomed Online 2006;13:64550 .

25. Kably Ambe A, Estévez González S, Carballo Mondragón E, Durán Monterrosas L. Análisis comparativo de la tasa de embarazo-ovocitos capturados en un programa de fertilización in vitro [Comparative analysis of pregnancy rate/captured oocytes in an in vitro fertilization program]. Ginecol Obstet Mex 2008;76:256-60. 